\title{
Measuring and Predicting Intention of Senegalese Mothers to Provide Iron-Rich Foods to their Children
}

\author{
Kossi Akpaki ${ }^{*}$, Isabelle Galibois ${ }^{1}$ and Sonia Blaney ${ }^{2}$ \\ ${ }^{1}$ School of Nutrition, Laval University, Quebec City, Quebec, G1V 0A6, Canada \\ ${ }^{2}$ School of Food Sciences, Nutrition and Family Studies, Moncton University, Moncton, New Brunswick, E1A \\ 3E9, Canada
}

\begin{abstract}
In Senegal, only $43 \%$ of children aged 6-23 months are provided with iron-rich foods (IRF). Assessing determinants of mothers' behaviour is imperative to improve young children nutrition. We developed a validated questionnaire and used it to assess psychosocial factors of mothers' intention to provide IRF to their children aged 6-23 months in the Matam area, Senegal. Using the planned behaviour theory, the first version of a questionnaire was developed and administered to 120 mothers. Exploratory factorial analyses (EFA) were used to generate a shorter and validated final version of the questionnaire, administered to another sample $(\mathrm{N}=100)$ of mothers to assess psychosocial factors underlying their intention to provide IRF to children. EFA revealed the importance of perceived benefits mothers have for the health/welfare of their children if providing them IRF, about acting according to expectations of persons in their surroundings and limited access to IRF due to physical/financial constraints. Attitude $(\beta=0.26, p=0.015)$ and subjective norm $(\beta=0.22, p=0.047)$ were positively associated with mothers' intention to provide IRF to their children. Together with sociodemographic variables, they explained $14 \%$ of its variance. Our findings revealed that mothers have a strong intention to provide IRF to their children. Although further assessments of this questionnaire are warranted in other contexts, this tool could provide information on potential determinants of mothers' intention to provide IRF to children.
\end{abstract}

Keywords: Intention, Mothers, Theory of planned behaviour, Iron-rich foods, Senegal.

\section{INTRODUCTION}

Worldwide, the prevalence of anaemia (defined as a haemoglobin concentration below the threshold of 110 or $120 \mathrm{~g} / \mathrm{L}$ respectively for children under-five and nonpregnant women aged 15 years and above) remains high, especially in Sub-Saharan Africa (SSA) [1, 2]. In this region, iron-deficiency anaemia is prevalent in infants and young children under two years of age, given the high iron requirements for rapid growth and development [3]. The consequences of iron deficiency anaemia in early life are severe and have been largely documented [3]. Amongst young children, iron deficiency impacts their cognitive development, may damage their immune system, and has been associated with increased morbidity rates [1, 3]. Socioeconomic, behavioural and environmental factors may increase child vulnerability to anaemia through their influence on the intake of iron-rich foods (IRF) [3]. For example, poverty has been shown to be associated with adverse health and nutrition behaviour, including poor dietary practices, which can affect iron status. In addition, food insecurity may also affect the quality of young children diet by limiting their access to IRF [3]. For instance, in rural Ethiopia, households having animal source foods were 4.8 times more likely to have children who consumed these foods [4]. Besides,

*Address correspondence to this author at the School of Nutrition, Laval University, Pavillon Paul-Comtois, 2425 rue de l'Agriculture, Québec City, QC, G1V 0A6, Canada; Tel: +1 (418) 656-2131 ext. 402904;

E-mail: kossi.akpaki.1@ulaval.ca children of mothers who had no education were $8 \%$ more likely to be anaemic than children of mothers with a secondary or higher education [5]. Cultural beliefs may also shape mother patterns toward the child diet [3].

Behaviour-change communication (BCC) strategies have been used to increase the consumption of IRF amongst young children [6]. In Ethiopia, a large-scale social and BCC intervention was associated with the improvements of infant and young child feeding practices indicators [6]. To be effective, BCC strategies must be based upon behavioural and social science theories. Also, BCC strategies should be informed by an appropriate understanding of the local context as well as on evidence [7]. So far, studies have been conducted to investigate determinants of the limited consumption of IRF amongst young children, such as social behaviours and environmental factors [8, 9]. Unfortunately, in SSA countries, less attention has been dedicated to this topic. Research aiming at investigating determinants of limited nutrition practices should be guided by a theoretical framework to identify key psychosocial factors associated with these behaviours [10-12].

Overall, surveys designed to evaluate psychosocial factors that determine the caregiver's intention related to health and nutrition issues affecting young children are scarce, especially in rural areas of SSA countries, as are measurements to assess these determinants 
[13]. Tools such as questionnaires have been developed and validated in high-income contexts to predict mothers' decision to breastfeed or to provide complementary foods to their children, either in a selfadministered format $[14,15]$ or administered by interviewers [16]. However, self-administrated questionnaires are not suitable for studies amongst the population with a low literacy level. Although a questionnaire administrated by an interviewer may induce a social desirability and interviewer bias [17], it remains the only mode of questionnaire administration in a low literacy context. In SSA countries, limited formal education and poor young child feeding practices are widespread [18]. Thus, designing a valid tool to investigate determinants of the inadequate consumption of IRF amongst young children in these populations would be valuable. It could also contribute to the definition of $\mathrm{BCC}$ strategies for reducing iron deficiency anaemia amongst this group.

Recent data indicate that Senegal ranked amongst the top countries in terms of the prevalence of anaemia in children below 5 years of age [19]. The prevalence of anaemia amongst this group increased from $60 \%$ to $71 \%$ between 2014 and 2018 [20, 21]. The quality of complementary food amongst children aged 6-23 months is poor, as only $8 \%$ were fed according to WHO recommendations [21]. Moreover, data reveal that only $43 \%$ had consumed IRF the day preceding the survey [21]. Additionally, food insecurity remains a critical issue in Senegal. In 2016, around $20 \%$ of households were food insecure [22]. During the past years, the situation of food insecurity has been particularly worrisome in some regions such as Matam [23, 24], where around $40 \%$ of its population have been reported to be food insecure [25]. Furthermore, the Matam region shows the highest rate of wasting $(15.0 \%)$ amongst children under five years of age [21]. Improving the consumption of IRF amongst children aged 6-23 months could reduce iron deficiency anaemia amongst this group [3,26], and it is a priority for the government of Senegal [27].

The theory of planned behaviour (TPB) [28] was used as the theoretical framework to guide this research. Despite some limitations, the TPB has been used to study factors underlying eating behaviour and was shown to be rather good for explaining the intention [29]. In fact, the intention was the most important predictor of the behaviour, and the perceived behavioural control added significantly to the prediction [29]. Even though the efficiency of the TPB certainly varies across health-related behaviours, about $47 \%$ and $32 \%$ of the variation of a health behaviour appears to be explained by the effect of the intention and the perceived behavioural control, respectively [29]. In addition, several studies have used the TPB to predict a mother's decisions, either the intention or the behaviour itself, about infant and young child feeding practices [14, 30-32]. Hamilton et al.'s [14] findings have shown that the intention was associated with introducing complementary foods, explaining more than $30 \%$ of its variance slightly along with the mother's age and weight status. The TPB model was also rather good in explaining the intention of a mother's dietary decisions toward her young child [14, 30]. Brophy-Herb et al. [32] have highlighted the importance of mothers attitudes about feeding practices and roles of family members over behaviours regarding mothers' decisions to introduce foods. Similarly, Heinig et al. [33] have also used the TPB to identify beliefs underpinning the introduction of foods to infants. Finally, in rural Kenya, an extended version of TPB has been used to assess the psychosocial predictors of women's intention to integrate biofortified pro-vitamin A orangefleshed sweet potato in child feeding [34].

This research aimed to develop a validated questionnaire and use it to assess the relationship between psychosocial factors and the intention of Senegalese mothers to provide IRF to their children aged 6-23 months in the Matam area, Senegal.

\section{MATERIALS AND METHODS}

\section{Study Design and Setting}

A cross-sectional study was conducted in Matam, Northeast Senegal, where the prevalence of anaemia amongst children under five is at $73 \%$ [35]. This is the second-largest region of the country, with an area of 29 $616 \mathrm{~km}^{2}$. The population is estimated at 654981 inhabitants [35], and it is composed essentially of the " Pulaar » ethnic group. Matam is also one of the poorest regions in Senegal, with $45 \%$ of its population below the poverty rate compared to $38 \%$ at the national level $[36,37]$. The climate is semi-desertic, characterised by alternating the long dry season (November to June) and the short rainy season (July to October). Nearly $60 \%$ of the population practice subsistence agriculture, and $11 \%$ practice transhumance from the "silvopastoral" zone to the central and eastern of the region [38]. These conditions make this region one of the most vulnerable of the country to food and nutrition security. Indeed, our team recently reported that almost two-thirds of the region's households were severely food insecure [39]. 


\section{Sampling}

Two samples of mothers of children aged 6-23 months were recruited in the study setting. The first sample (sample $\# 1, N=103$ ) represents the main sample of the research in which relationships between mothers' psychosocial factors and their intention to give IRF to their children aged 6-23 months were investigated. Other factors, such as community and household food environments, were also investigated amongst sample \#1 and results on this component have been published in a previous paper [39]. The second sample (sample \#2, $N=120$ ) was selected only for the validation process of the questionnaire. All mothers of children aged 6-23 months were invited to participate in the research voluntarily.

Sample \#1 included mothers from households randomly selected in four villages of the region [39]. The sample size was determined with the $G^{*}$ Power software $[40,41]$ to allow power analyses for testing that proportion of variance of our dependent variable (daily consumption of IRF) would be explained by a set of five predictors, which are the followings: a) intention, b) PBC and c) food environment factors namely the number of foods available at the community level, number of foods available at household level and household food insecurity score ( $G$ * Power 3.1 manual March 1, 2017). A significance level (a) of $5 \%$, a statistical power of $80 \%$ and a medium effect size of 0.15 were used to calculate the sample size. Given the absence of data about the variance associated with the behaviour under study, the sample size calculation was based on a medium-size effect of 0.15 . A non-response rate of $10 \%$ was considered to calculate the required sample size, which was 102 mothers of children aged 6-23 months.

The following steps, described previously [39], were used to select mothers for sample \#1. In short, two departments, Matam and Kanel, were purposively chosen out of the three that composed the region of Matam. In each department, one municipality was randomly selected, and, in each municipality, two villages were randomly chosen: NdouloumadjiFounebe (NF) and Sinthiou Mogo (SM) in the Matam department and Thiemping (TP) and Thialy Maka (TM) in the Kanel department. In each village, all households with one or more children aged 6-23 months were listed. In NF, 68 households were identified, 71 in SM, 92 in TP, and 93 in TM. In each village, 25 (TP) or 26 (NF, SM, and TM) households were randomly selected.
Households and mothers of sample \#2 were recruited in two different purposively selected villages in the same area so that mothers in samples \#1 and \#2 would have similar sociodemographic characteristics.

Data on household composition, housing conditions and ownership of assets were gathered on sample \#1 with a standardised questionnaire through an interview conducted with the head of household. In sample \#2, data on the age and education level of the child's mother as well as on the age and sex of the child were gathered using a short version of the aforementioned questionnaire.

\section{Theoretical Framework}

The TPB was used as the theoretical framework for the development of the questionnaire [28]. This theory states that a person's intention to either perform or not perform a behaviour is the first determinant of the behaviour. A person's intention represents his/her motivation towards the adoption of behaviour, and it is determined by three constructs: the attitude toward the behaviour (ATT), the subjective norm (SN), and the perceived behavioural control (PBC) [28].

ATT is determined by a person's beliefs about the behaviour (behavioural beliefs) and their evaluation of the consequences of adopting it (consequences evaluation). It is a subjective judgment of the behaviour and of its consequences [28].

$\mathrm{SN}$ is determined by the importance a person gives to the opinions of people or groups of people around him/her (normative beliefs) and by the motivation to follow these opinions (motivation to comply) [28, 42].

PBC is the degree of control a person believes he/she can exercise over a given behaviour (control beliefs) and by the perception of ease or difficulty (perceived power of control factors) with which behaviour can be adopted [42]. In addition, PBC measures a person's sense of self-efficacy in relation to the behaviour, but it can also directly predict the behaviour [28, 42].

\section{Questionnaire Development Process}

The questionnaire was developed according to the approach described by Gagné and Godin [43] and the methodological recommendations of Ajzen [44].

\section{Focus Group Discussions (FGD)}

This step was conducted with a sub-sample $(\mathrm{N}=50)$ of sample \#1 of mothers. First, a discussion guide was 
developed based on Gagné and Godin's work [43] to identify salient beliefs related to the daily consumption of IRF by their children aged 6-23 months. This guide was used to conduct one FGD with mothers of children aged 6-23 months in each of the four villages. In each FGD, mothers were asked to express their beliefs about the following: 1) advantages and disadvantages of giving IRF daily to their children aged 6-23 months (ATT), 2) persons or groups of persons who would approve or disapprove of the behaviour mentioned above (SN) and, 3) opportunities and barriers to implementing the behaviour (PBC). All FGDs were conducted in the local language "Pulaar" by interviewers, and they were tape-recorded. The average duration was one hour per FGD, with 12 to 13 participants in each group. Transcriptions in French were carried out by one of the interviewers.

Afterwards, the first author of the article (K.A.) conducted a qualitative analysis of the transcriptions (K.A.) to identify salient beliefs related to each of the three constructs based on Rabiee's recommendations [45]. As such, for each question, the contents of the transcription were read several times; keywords/ideas or concepts were highlighted in colour for each question. Statements supporting ideas/concepts were also highlighted, and answers to a different question were put under the appropriate question [45]. The salient beliefs identified during FGDs (Appendix Table 1) were formulated as an item in the questionnaire.

\section{Questionnaire Construction}

All aforementioned salient beliefs were used as the primary source for the formulation of items for each construct (ATT, SN, PBC) to be assessed through the questionnaire. Items to assess the intention of providing IRF to children were also included. The initial questionnaire included a total of 67 items (Appendix Table 2).
Graphic answer scales were used for all items of the questionnaire. Except for the first 8 items of MC, the graphic answer scales for all items were accompanied by Likert-type answer scales using pictograms of angry/smiley faces (Figure 1). Pictures of the two smileys/angry faces in the upper part of Figure 1 were provided by the London School of Tropical Medicine and Hygiene to the Institut de Population, Développement et Santé de la Reproduction (IPDSR) at the Cheick Anta Diop University (UCAD, Dakar, Senegal) for use in an unpublished study conducted on maternal health services in Senegal. Pictures of a face with hands on the mouth as well as of thumbs used to illustrate the five answer options of the Likert scale (lower part of Figure 1) were found on the internet. For the first 8 items of MC, the graphic answer scale used was a visual ordinal scale adapted from a study conducted in Benin [46].

The above process was completed by discussions between the authors of this paper to ensure that all different items were clear and simple enough before administering the questionnaire to sample \#2. Additionally, simulation exercises were carried out with ten master's degree students of the IPDSR to check out the clarity and simplicity of every item.

\section{Questionnaire Administration for Validation}

The initial questionnaire was administered to sample \#2 (120 mothers of children aged 6-23 months) in May 2018 through individual interviews conducted by trained enumerators during home visits. Before initiating its administration, the interviewer explained to each participant how to express answers to questions on each scale.

Regarding the five-answer options scale with pictograms (Figure 1), the interviewers first explained that the two extreme opposite pictograms (an angry

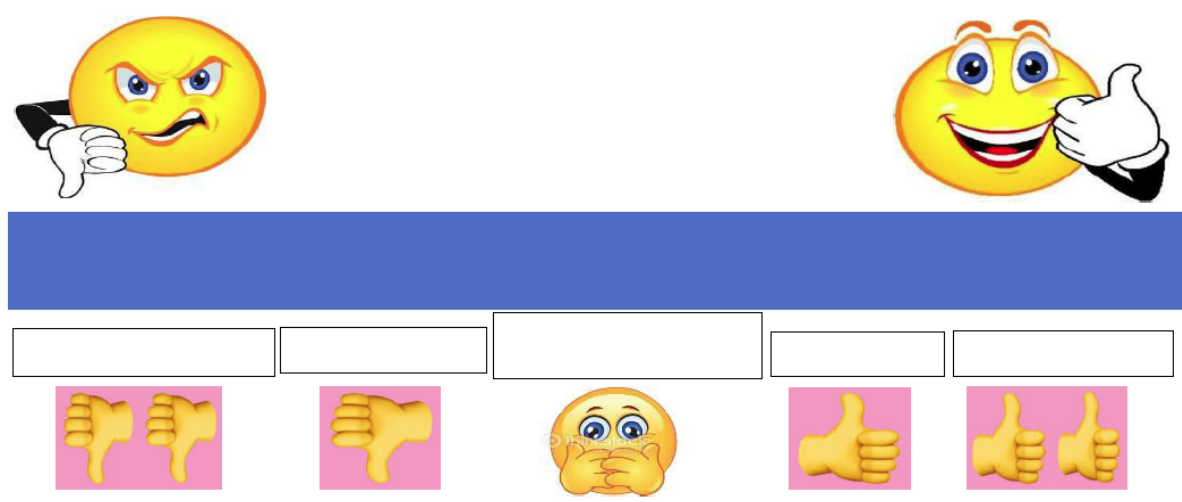

Figure 1: Five points Likert-type answer scale with pictograms. 
face at the far left and a smiley face at the far right of each scale) reflected bipolar adjectives that could mean, depending on the formulation of the question or statement read by the interviewer, answers such as "disagree/agree» or " not important/important». Following the explanation of each scale, the interviewer administrated the questionnaire, reading item by item and asking the participant to put her finger on or mark with a pen the selected answer on each respective scale.

\section{Data Analysis for Questionnaire Validation}

For all items with the five-answer options Likert scale with pictograms, answers were scored from 1 to 5 or from 5 to 1 in case of inverted item formulation. The eight items of the questionnaire (none was inverted) that used the four answer options shaded ordinal scale was scored from 1 to 4 . Frequency distributions were produced for each item to check for missing data.

Principal component analyses (PCA) were initially conducted on all items related to each of the constructs, namely attitude (20 items), social norm (32) and the perceived behavioural control (12). In order to simplify the questionnaire, several PCA was run to reduce the number of items under each construct as much as possible while still respecting the assumptions for sampling adequacy (having a Kaiser-MeyerOlkin/KMO value $>0.70$ ) and ensuring that correlations between items were strong enough (Bartlett's test < 0.05) for PCA [47] (Appendix Table 3). A KMO value between 0.70 and 0.80 was considered acceptable, and from 0.80-0.90 was very good [47]. A p-value below 0.05 for Bartlett's test indicates the presence of intra-items correlations, and it shows the suitability of the data for the EFA [47]. For each construct, EFA was conducted on final models using an orthogonal rotation (varimax). Factors with eigenvalues having a Kaiser's criterion above 1 were retained, and the proportion of variance explained by each factor was reported.

The reliability of the final questionnaire was assessed using the Guttman test [48, 49]. Guttman's Lambda-2 ( $\lambda 2)$ was retained as the criterion for interpreting the reliability test of the questionnaire, given its robustness [48].

\section{Assessment of the Intention and its Predictors}

The final validated questionnaire was administered to mothers of sample \#1 in June and July 2018 through face-to-face interviews.

\section{Statistical Analyses on Predictors of the Intention}

All statistical analyses were performed with the IBM SPSS Statistics for Windows, Version 23. (Armonk, NY: IBM Corp).

Descriptive statistics (means, frequency distributions) were performed. Mean scores and standard deviations were calculated for each item of the final questionnaire. For each construct underlying the TPB, the mean scores were first calculated for its sub-construct by summing the average score of each item that composed the sub-construct. After that, the mean scores of each construct were calculated by multiplying the average scores of its sub-constructs [50]. T-test for an independent sample and chi-square test were used respectively to determine differences in mean age and education level of child's caregivers between the two samples.

Hierarchical linear multiple regression techniques were used to identify predictors of the mothers' intention to provide their children with IRF. First, individual scores on each construct of the TPB were entered in the regression model along with the mean score on the intention. Thereafter, sociodemographic variables (age and education level of caregivers, household economic status, and household size) were entered in subsequent steps. Prior to multiple linear regression analysis, the assumption of multicollinearity and homoscedasticity were checked by using the Variance Inflation Factors (VIF) less than 10 for all predictors [51] and the Koenker test [52], respectively. Overall, the regression model produced VIF below 10 for all predictors; the Koenker test was not significant $(p=0.072)$, suggesting a non-violation of multicollinearity and homoscedasticity, respectively. However, the assumption of normality of the data distribution on intention was verified but unmet given the skewed distribution. For all tests, a p-value $<0.05$ was used as a threshold for statistical significance.

\section{RESULTS}

Characteristics of households included in the two samples of the study are shown in Table 1. In sample 1 , around 3 out of 4 household heads were male and more than 7 out of 10 had no formal education. The average age of the household head was $53.7 \pm 15.6$ years (standard deviation), and on average, a household was composed of $13.5 \pm 8.6$ members. The average age of the child's mother was $28.5 \pm 7.4$ years, and around 5 out of 10 had no formal education. In 
sample 2, the average age of the child's mother was $27.3 \pm 7.5$ years, and around 5 out of 10 had no formal education. There was no statistical difference between the two samples regarding the mean age of the child's mother or their education level. In sample \#1, mean household socioeconomic scores differed from the lower to the highest terciles [39]. During the data collection, amongst sample \#1 for whom 103 households had been recruited, three mothers were absent and could not be interviewed, leading to a final sample size of 100 .

Table 1: Description of the Samples under Study

\begin{tabular}{|c|c|c|}
\hline Characteristics (\%) & $\begin{array}{l}\text { Sample } 1 \\
(N=100)\end{array}$ & $\begin{array}{l}\text { Sample } 2 \\
(N=120)\end{array}$ \\
\hline \multicolumn{3}{|l|}{ Gender of HH head } \\
\hline Male & 73.0 & \\
\hline Female & 27.0 & \\
\hline \multicolumn{3}{|l|}{ Age of HH head (years) } \\
\hline $15-29$ & 3.0 & \\
\hline $30-44$ & 33.0 & \\
\hline $45+$ & 64.0 & \\
\hline \multicolumn{3}{|l|}{ HH size } \\
\hline $1-5$ & 7.0 & \\
\hline $6-10$ & 36.0 & \\
\hline$>10$ & 57.0 & \\
\hline \multicolumn{3}{|l|}{ Education level of $\mathrm{HH}$ head } \\
\hline None & 73.0 & \\
\hline Primary & 21.0 & \\
\hline Middle or higher & 6.0 & \\
\hline \multicolumn{3}{|l|}{ Age (years) of child's mother } \\
\hline $15-29$ & 58.0 & 65.8 \\
\hline $30-44$ & 40.0 & 31.7 \\
\hline $45+$ & 2.0 & 2.5 \\
\hline \multicolumn{3}{|c|}{ Education level of child's mother } \\
\hline None & 53.0 & 51.7 \\
\hline Primary & 29.0 & 30.0 \\
\hline Middle or higher & 18.0 & 18.3 \\
\hline
\end{tabular}

\section{Questionnaire Validation}

In total, six (6), four (4) and three (3) PCA were respectively conducted on items part of each construct underlying the intention to implement the behaviour. $\mathrm{KMO}$ values of final models were $0.73,0.85$ and 0.83 for the ATT (12 items), subjective norm (16) and PBC
(10) constructs. P values of Bartlett's test of sphericity were all below 0.05 . Eigenvalues from the EFA on each construct were extracted from the analysis on the final models (Table 2). For the construct on attitude, four factors had eigenvalues over the Kaiser's criterion of 1 , and the combination of the four factors explained $73,08 \%$ of the variance while three factors for the SN and two factors for PBC constructs had eigenvalues above 1 , explaining $83,13 \%$ and $77,35 \%$ of their respective variance.

The results on factor loadings are also presented in Table 2. For the attitude, factor \#4, which comprises five items as well as factor \#6 with three items, both show the importance amongst mothers of health and the overall welfare aspects of providing IRF to the child. On the other hand, the three items loading on factor \#7 were all related to the potential negative consequences of providing these foods. For the social norm, items were tapping in the perception of mothers about the approval/disapproval of several persons in her surroundings to provide IRF to her child but also about her as acting according to their expectations. The perceived behavioural control, which consists of 10 items, refers to the limited access to IRF due to physical or financial constraints.

A final PCA combining all the remaining 40 items of the questionnaire was conducted. The $\mathrm{KMO}$ value (0.71) and the results of the Bartlett test $(0.00)$ were again respecting the above assumptions. Results of the EFA show that eight factors had eigenvalues above 1 , and factor \#1 was explaining $28.77 \%$ of the variance. The result of Guttman's test was 0.91 for the final questionnaire.

\section{Mothers' Scores of Intention, Constructs and Sub- Constructs to Provide IRF to their Children}

For mothers of sample \#1 who were administered the final questionnaire, the mean scores of their intention to provide IRF and of each of its constructs and sub-constructs are displayed in Table 3. Overall, mean scores of individual items included in the final questionnaire were above 4 (out of 5) with the exception of one BB item: If you give your child an ironrich food like fish, the bones will block his/her throat, and of two CB items: The absence of iron-rich foods in the market could prevent me from giving iron-rich foods to my child aged 6-23 months at least once a day, and The absence of iron-rich foods in my household could prevent me from giving iron-rich foods to my child aged 6-23 months at least once a day (Table 3). 
Table 2: Summary of the Exploratory Factor Analysis Results for Items of each Construct of the Intention Questionnaire ( $N=120)$

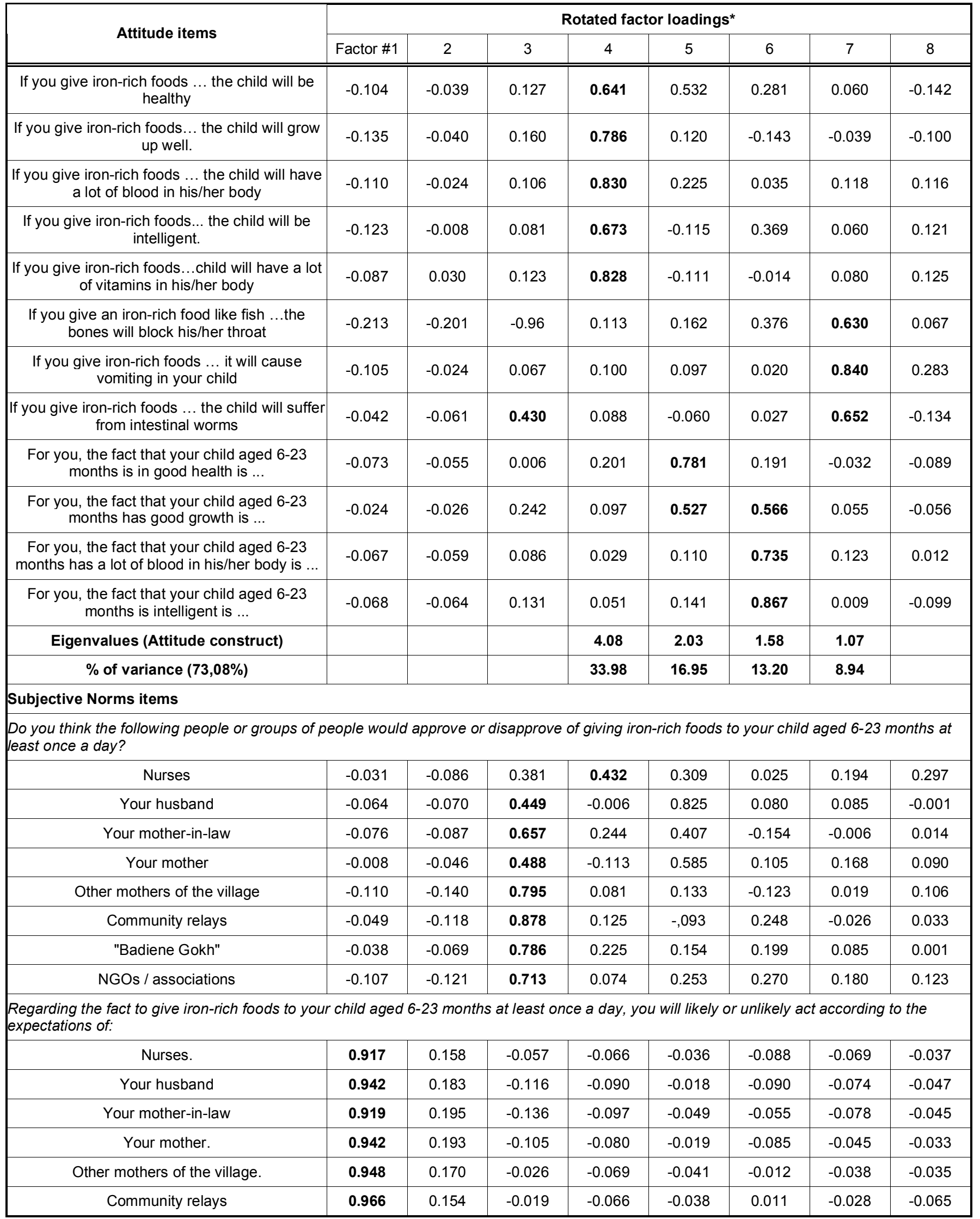


(Table 2). Continued.

\begin{tabular}{|c|c|c|c|c|c|c|c|c|}
\hline \multirow{2}{*}{ Attitude items } & \multicolumn{8}{|c|}{ Rotated factor loadings* } \\
\hline & Factor \#1 & 2 & 3 & 4 & 5 & 6 & 7 & 8 \\
\hline "Badiene Gokh". & 0.964 & 0.150 & -0.012 & -0.086 & -0.021 & 0.000 & -0.031 & -0.042 \\
\hline NGOs / associations. & 0.967 & 0.151 & 0.029 & -0.065 & -0.043 & 0.000 & -0.028 & -0.062 \\
\hline Eigenvalues (Subjective norm construct) & 7.92 & & 4.28 & 1.11 & & & & \\
\hline$\%$ of variance SN $(83.13 \%)$ & 49.47 & & 26.72 & 6.94 & & & & \\
\hline \multicolumn{9}{|l|}{ Perceived behavioural control items } \\
\hline $\begin{array}{l}\text { If I have iron-rich foods in my household... at } \\
\text { least once a day }\end{array}$ & -0.125 & -0.198 & 0.074 & 0.015 & -0.075 & -0.019 & 0.024 & 0.653 \\
\hline $\begin{array}{l}\text { If iron-rich foods cost less in the market... at } \\
\text { least once a day }\end{array}$ & -0.073 & -0.098 & 0.111 & 0.262 & -0.023 & -0.125 & 0.223 & 0.690 \\
\hline $\begin{array}{l}\text { The lack of financial means ... at least once a } \\
\text { day. }\end{array}$ & 0.042 & 0.705 & -0.077 &, 101 & -0.065 & -0.080 & 0.079 & -0.372 \\
\hline $\begin{array}{l}\text { The absence of iron-rich foods in the market } \\
\text {... at least once a day. }\end{array}$ & 0.147 & 0.785 & -0.091 & 0.055 & -0.056 & -0.135 & 0.036 & -0.337 \\
\hline $\begin{array}{l}\text { The absence of iron-rich foods in my } \\
\text { household... at least once a day. }\end{array}$ & 0.149 & 0.723 & -0.031 & 0.092 & -0.052 & -0.183 & 0.136 & -0.381 \\
\hline $\begin{array}{l}\text { The expensiveness of iron-rich foods .... at least } \\
\text { once a day. }\end{array}$ & 0.203 & 0.765 & -0.089 &,- 017 & -0.037 & -0.108 & -0.176 & -0.131 \\
\hline The lack of financial means is a... obstacle & 0.118 & 0.843 & -0.101 & -0.034 & -0.040 & -0.010 & 0.014 & 0.000 \\
\hline $\begin{array}{l}\text { The absence of iron-rich foods in the market is } \\
\text { a...obstacle }\end{array}$ & 0.222 & 0.864 & -0.049 & -0.046 & -0.008 & 0.024 & -0.080 & 0.058 \\
\hline $\begin{array}{l}\text { The high cost of iron-rich foods in the market is } \\
\qquad \text { a ...obstacle. }\end{array}$ & 0.265 & 0.773 & -0.111 & -0.151 & 0.067 & 0.117 & -0.162 & 0.192 \\
\hline $\begin{array}{l}\text { The absence of iron-rich foods in my home is a } \\
\qquad \ldots \text { obstacle. }\end{array}$ & 0.292 & 0.798 & -0.077 & -0.098 & -0.075 & 0.048 & -0.118 & 0.105 \\
\hline Eigenvalues (PBC construct) & & 5.37 & & & & & & 1.29 \\
\hline$\%$ of variance PBC (77.35\%) & & 53.70 & & & & & & 12.86 \\
\hline Eigenvalues & 10.932 & 5.431 & 3.879 & 2.499 & 2.108 & 1.719 & 1.363 & 1.262 \\
\hline$\%$ of the variance $(76.82 \%)$ & 28.768 & 14.291 & 10.208 & 6.576 & 5.547 & 4.525 & 3.588 & 3.320 \\
\hline
\end{tabular}

${ }^{*}$ Factor loadings over 0.40 are in bold.

Table 3: Mean Scores ( \pm Standard Deviation/ SD) for each Item of the Final Questionnaire $(N=100)$

\begin{tabular}{|c|c|c|}
\hline Constructs & Items & Mean \pm SD \\
\hline \multirow[t]{3}{*}{ Intention } & I intend to give iron-rich foods ... at least once a day. & $4.85 \pm 0.44$ \\
\hline & I will give iron-rich foods... at least once a day & $4.84 \pm 0.62$ \\
\hline & All & $4.84 \pm 0.47$ \\
\hline Attitude & $\left(\mathbb{\Sigma}\left(B B^{\star} E C\right)\right)$ & $23.17 \pm 1.92$ \\
\hline \multirow{9}{*}{$\begin{array}{l}\text { Behavioural beliefs } \\
\text { (BB) }\end{array}$} & If you give iron-rich foods ... the child will be healthy. & $4.95 \pm 0.22$ \\
\hline & If you give iron-rich foods... the child will grow up well. & $4.93 \pm 0.29$ \\
\hline & If you give iron-rich foods ... the child will have a lot of blood in his/her body. & $4.95 \pm 0.26$ \\
\hline & If you give iron-rich foods... the child will be intelligent. & $4.84 \pm 0.49$ \\
\hline & If you give iron-rich foods... a child will have a lot of vitamins in his/her body. & $4.98 \pm 0.14$ \\
\hline & If you give an iron-rich food like fish ...the bones will block his/her throat. & $3.86 \pm 1.26$ \\
\hline & If you give iron-rich foods ... it will cause vomiting in your child. & $4.37 \pm 0.97$ \\
\hline & If you give iron-rich foods ... the child will suffer from intestinal worms. & $4.33 \pm 1.06$ \\
\hline & All & $4.65 \pm 0.37$ \\
\hline
\end{tabular}


(Table 3). Continued.

\begin{tabular}{|c|c|c|}
\hline Constructs & Items & Mean \pm SD \\
\hline \multirow{5}{*}{$\begin{array}{l}\text { Evaluation of consequences } \\
\qquad(E C)\end{array}$} & For you, the fact that your child aged $6-23$ months is in good health is ... & $4.95 \pm 0.41$ \\
\hline & For you, the fact that your child aged $6-23$ months has good growth is ... & $5.00 \pm 0.00$ \\
\hline & $\begin{array}{c}\text { For you, the fact that your child aged } 6-23 \text { months has a lot of blood in his/her } \\
\text { body is ... }\end{array}$ & $4.97 \pm 0.22$ \\
\hline & For you, the fact that your child aged $6-23$ months is intelligent is ... & $5.00 \pm 0.00$ \\
\hline & All & $4.98 \pm 0.12$ \\
\hline Subjective norm & $\left(\sum\left(N B^{*} M C\right)\right)$ & $21.16 \pm 4.22$ \\
\hline \multirow{9}{*}{$\begin{array}{l}\text { Normative beliefs (NB) } \\
\text { Do you think the following people or } \\
\text { groups of people would approve or } \\
\text { disapprove of giving iron-rich foods to } \\
\text { your child aged } 6-23 \text { months at least } \\
\text { once a day? }\end{array}$} & Nurses & $4.94 \pm 0.28$ \\
\hline & Your husband & $4.96 \pm 0.24$ \\
\hline & Your mother-in-law & $4.85 \pm 0.50$ \\
\hline & Your mother & $4.91 \pm 0.40$ \\
\hline & Other mothers of the village & $4.70 \pm 0.69$ \\
\hline & Community relays & $4.87 \pm 0.51$ \\
\hline & "Badiene Gokh" & $4.90 \pm 0.44$ \\
\hline & NGOs/Associations & $4.90 \pm 0.36$ \\
\hline & All & $4.88 \pm 0.30$ \\
\hline \multirow{9}{*}{$\begin{array}{l}\text { Motivation to comply (MC) } \\
\text { Regarding the fact to give iron-rich } \\
\text { foods to your child aged } 6-23 \text { months } \\
\text { at least once a day, you will likely or } \\
\text { unlikely act according to the } \\
\text { expectations of: }\end{array}$} & Nurses & $4.27 \pm 1.03$ \\
\hline & Your husband & $4.51 \pm 0.75$ \\
\hline & Your mother-in-law & $4.33 \pm 0.92$ \\
\hline & Your mother & $4.39 \pm 0.89$ \\
\hline & Other mothers of the village & $4.08 \pm 1.03$ \\
\hline & Community relays & $4.35 \pm 0.95$ \\
\hline & "Badiene Gokh" & $4.40 \pm 0.88$ \\
\hline & NGOs/Associations & $4.34 \pm 0.90$ \\
\hline & All & $4.33 \pm 0.80$ \\
\hline Perceived behaviour control & $\left(\sum\left(C B^{*} P\right)\right)$ & $19.27 \pm 5.17$ \\
\hline \multirow[t]{7}{*}{ Control beliefs (CB) } & If I have iron-rich foods in my household... at least once a day. & $4.98 \pm 0.14$ \\
\hline & If iron-rich foods cost less in the market... at least once a day. & $4.77 \pm 0.60$ \\
\hline & The lack of financial means ... at least once a day. & $4.45 \pm 1.08$ \\
\hline & The absence of iron-rich foods in the market ....at least once a day. & $3.97 \pm 1.31$ \\
\hline & The absence of iron-rich foods in my household... at least once a day. & $3.97 \pm 1.30$ \\
\hline & The expensiveness of iron-rich foods .... at least once a day. & $4.16 \pm 1.16$ \\
\hline & All & $4.38 \pm 0.66$ \\
\hline \multirow{5}{*}{$\begin{array}{l}\text { The perceived power of control } \\
\qquad(\mathrm{P}) \text { factors }\end{array}$} & The lack of financial means is a... obstacle & $4.67 \pm 0.59$ \\
\hline & The absence of iron-rich foods in the market is a...obstacle. & $4.08 \pm 1.11$ \\
\hline & The high cost of iron-rich foods in the market is a ...obstacle. & $4.47 \pm 0.76$ \\
\hline & The absence of iron-rich foods in my home is a ...obstacle. & $4.11 \pm 1.15$ \\
\hline & All & $4.33 \pm 0.72$ \\
\hline
\end{tabular}

\section{Predicting Intention of Mothers to Provide IRF to their Children}

Results of the regression analyses show that ATT $(\beta=0.26, p=0.015)$ and $\mathrm{SN}(\beta=0.22, p=0.047)$ were positively associated with the intention of mothers to provide IRF to their children: both variables explained $12 \%$ of the variance associated with the intention (Table 4). In the second model, sociodemographic variables explained an additional $2 \%$ of the variance (Table 4).

\section{DISCUSSION}

The purpose of this study was firstly to develop a validated questionnaire and subsequently to use it to investigate the relationship between psychosocial factors and the intention of Senegalese mothers living 
Table 4: Predictors of the Mothers' Intention to Feed their Children with IRF Daily (N=100)

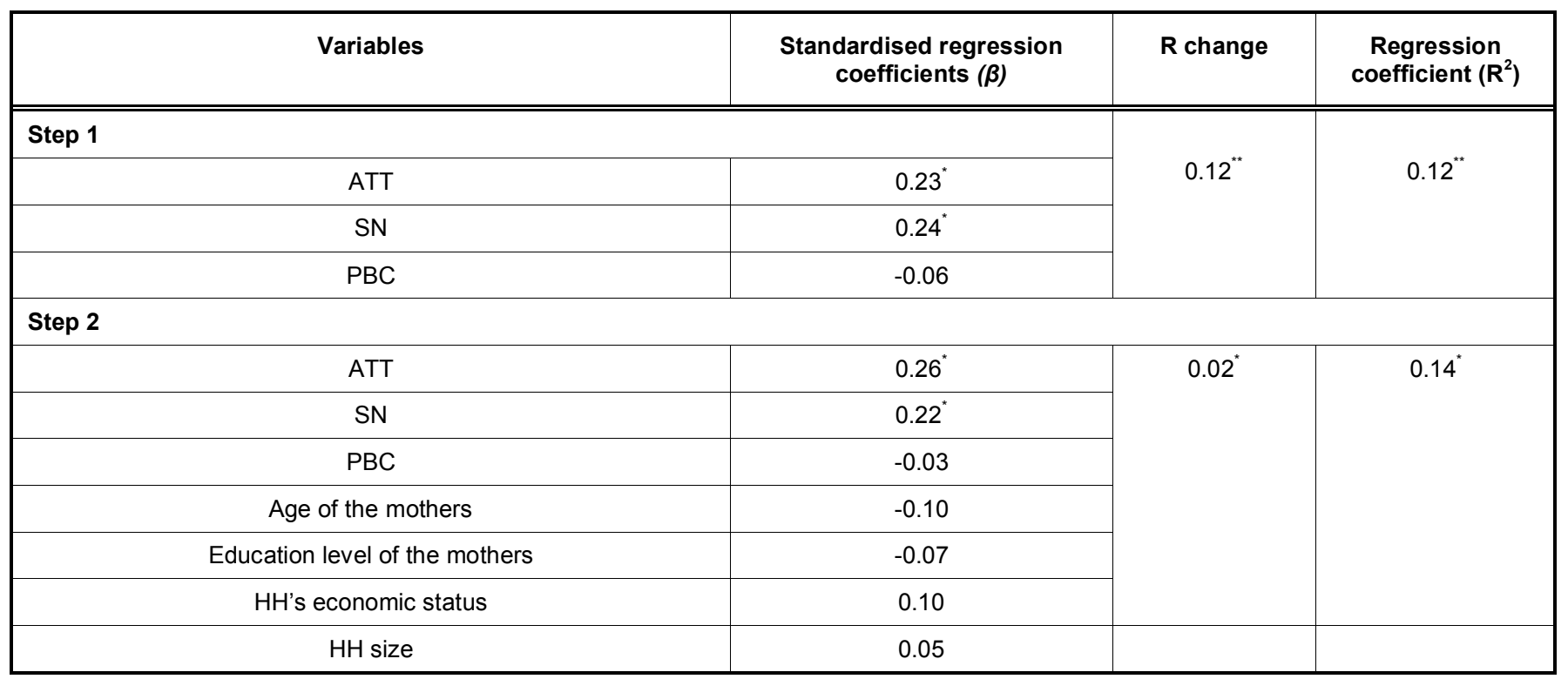

Note: ${ }^{*} p<0.05 ;{ }^{* *} p<0.01$. $\mathrm{HH}=$ household.

in a rural area to provide IRF daily to their 6-23 monthsold children. The TPB [28] was used as the theoretical framework to guide this research.

In the validation step, results from the EFA showed that for each construct, several items were clustering. With regards to attitude, five items were loading on one factor, and all of them were related to the health and welfare of the young child. One may assume that knowing the health benefits of providing IRF may shape the mothers' attitude towards the provision of IRF to young children favourably. There were several items loading on two different factors for the social norm construct. It appears that mothers perceived a wide range of persons as potentially approving or disapproving their provision of IRF to their children and may also be likely or not to act according to their perception. Similar to the social norm, there were several items loading on one factor for the construct on the perceived behavioural control: most of them were related to the physical and financial access to IRF, which concurs with the fact that household food security was an issue in the study area. Results from the EFA on the final questionnaire show that this tool could be used to assess each psychosocial factor (ATT, SN, PBC) related to the mothers' intention to provide IRF daily to their children in the critical age of 6-23 months. The eight factors that were generated from the EFA explained an important proportion of the variance. Furthermore, the final questionnaire appears to be a reliable tool [53]. In other words, if the questionnaire was used to evaluate the constructs under study in the same given population several times, similar results should be obtained each time.

In addition, pictograms of smiley/ angry faces and of thumbs up/thumbs down used in the questionnaire could certainly be used in future measurement tools as they proved to be adequate and understandable by participants with a low literacy level. The quality of data collection with standardised questionnaires has improved in LMIC in the last decades, but challenges in these areas remain of concern, especially in rural areas amongst populations with a low education level. Findings from other studies have also shown that various pictograms were effective for communicating health-related information to persons with a low education level [54-57]. According to Mansoor and Dowse [54], one way of addressing the low literacy issue in these groups is to use visual aids such as pictograms, which improve the comprehension of health-related information. For its part, the current study demonstrated the usefulness of such pictograms as part of research tools for measuring psychosocial factors that could subsequently contribute to improving the design of $\mathrm{BCC}$ interventions.

In the second step of this study using the validated questionnaire, the mean score on the intention of mothers to provide IRF daily to their children was elevated, indicating their high motivation to give these foods during the critical window of age 6-23 months. The score of intention did not vary widely between mothers. Moreover, the mean score of different constructs and sub-constructs were also elevated, 
which explain the high intention to implement the behaviour under study. Clearly, factors other than psychosocial determinants prevent child mothers from translating this intention into a behaviour since recent surveys showed that only $43 \%$ of young Senegalese children actually consume IRF [21]. Also, in the study area, we have observed that the availability of food and especially IRF, was limited at the household level [39]. More worrisome is that $64 \%$ of households were severely food insecure in this setting [39].

Studies that have used the TPB to investigate the relationship between the intention of parents in supporting/implementing positive dietary behaviours towards their children and its underlying factors had reported a proportion of the variance explained by the three constructs ranging from $16 \%$ to $65 \%$ (when sociodemographic characteristics were added to the model) $[14,16]$. Although not in LMIC, Hamilton et al. [14] found that the attitude was positively associated with the intention to introduce solids foods to children at 6 months of age amongst Australian mothers $(\mathrm{N}=375)$. In line with our findings, Swanson and Power [58] identified subjective norms as predictors of infant feeding intentions amongst mothers $(\mathrm{N}=203)$ in Scotland. In their study, Hamilton et al. [14] also found that the subjective norm is a predictor of mothers' intention to introduce complementary foods. In the current research, while a small proportion of the mothers' intention was explained by psychosocial factors, results revealed that amongst them, attitude and subjective norm were the main predictors of the intention to provide IRF to children aged 6-23 months in the study area. The significant role of the subjective norm as a predictor of the mothers' intention to give IRF to their children aged 6-23 months emphasises the importance of their perception about the role that important people or groups of people may have with regards to young child nutrition in the study area. Whether this perception is real or not remains under debate. However, it could be judicious to involve individuals such as grandmothers who may influence young child's diet in BCC activities since research from Africa and Asia reveals the central role of senior women, grandmothers in the nutrition/health of young children $[59,60]$. Also, in this study, participants indicated that their mothers and mothers-in-law would strongly approve of providing IRF daily to their young children. The current findings also indicate that $2 \%$ of caregivers' intention was explained by sociodemographic factors. Finally, albeit only $12 \%$ of the proportion of the variance associated with the intention of mothers to provide IRF to young children was explained, psychosocial factors still appear to have a role in determining their motivation to implement this behaviour.

\section{LIMITATIONS AND STRENGTHS OF THE STUDY}

The current study adds value to the corpus of available research on potential determinants of behaviour not widely practised in LMIC, namely the provision of IRF daily to young children, which put them at risk of poor nutrition outcomes. Specifically, our findings indicate that mothers have the intention to provide IRF daily to their children, which is an important finding. Our research has also led to the development of a validated and reliable questionnaire to assess psychosocial factors of the provision of IRF daily to young children in our study context. Despite these strengths, the relatively small sample used to validate the questionnaire is a limitation [61]. Further studies are thus warranted amongst larger populations and different contexts. In addition, in our study, EFA was used to identify the structure of the scale, a process that was guided by a theoretical framework. In the future, a confirmatory factorial analysis in a different sample could be performed to confirm the structure of the scale. Lastly, the results of our regressions analyses should be considered with caution, given that the assumption of the normality distribution was not met for the dependent variable to be predicted (intention).

\section{CONCLUSION}

In our context, mothers have the intention to provide IRF daily to their children, which is good news and maybe the result of behaviour change activities implemented so far. Other actions than behaviour change activities aiming at improving the mother's intention should likely be undertaken to increase the daily provision of IRF to young children. The investigation of environmental factors potentially impacting the provision of IRF to young children certainly deserves further attention. Our tool was also proven to be valid and reliable for assessing psychosocial factors that trigger or hamper the mothers' intention to feed their children with IRF daily, which is a valuable contribution to the current knowledge and may help to prevent iron deficiency anaemia.

\section{ACKNOWLEDGEMENTS}

We thank all participants for their contribution to this research. We are particularly grateful to Professor 
Mohamadou Sall, Director of the Institut de Population, Développement et Santé de la Reproduction (IPDSR) of the Cheick Anta Diop University, Dakar, Senegal, as well as to Professor Marie-Pierre Gagnon of Faculty of Nursing Sciences at Laval University for their insightful comments and support. We gratefully acknowledge statistical advice from Dr Jérémie B. Dupuis at Moncton University. Also, we are grateful to all enumerators who were involved in the data collection and analyses, as

\section{APPENDIX}

Appendix Table 1: Number of mentions of advantages, disadvantages, important persons/groups of persons, barriers and facilitating factors identified by mothers during discussions in each village regarding the provision of iron-rich foods daily to children 6-23 months old $(\mathrm{N}=50)$

\begin{tabular}{|c|c|c|c|c|c|}
\hline \multirow[t]{2}{*}{ Beliefs } & \multicolumn{4}{|c|}{ Villages } & \multirow[t]{3}{*}{ Total } \\
\hline & NF & SM & TM & TP & \\
\hline \multicolumn{5}{|l|}{ Advantages } & \\
\hline -Good growth & 4 & 0 & 16 & 8 & 28 \\
\hline -Lot of blood & 0 & 0 & 3 & 3 & 6 \\
\hline \multicolumn{6}{|l|}{ Disadvantages } \\
\hline - My child will get sick & 0 & 4 & 7 & 3 & 14 \\
\hline -Diarrhea & 0 & 3 & 3 & 0 & 9 \\
\hline -Vomiting & 1 & 2 & 0 & 0 & 3 \\
\hline \multicolumn{6}{|l|}{ Approving persons/groups of persons } \\
\hline -Nurse & 8 & 1 & 10 & 6 & 25 \\
\hline -Husband & 0 & 2 & 7 & 6 & 15 \\
\hline -NGOs /associations & 5 & 2 & 5 & 2 & 14 \\
\hline -Community health agent & 3 & 0 & 4 & 2 & 9 \\
\hline -Mother in law & 1 & 2 & 1 & 1 & 5 \\
\hline -Midwife & 0 & 0 & 0 & 4 & 4 \\
\hline -My mother & 1 & 1 & 1 & 1 & 4 \\
\hline -Other mothers in the village & 1 & 1 & 1 & 1 & 4 \\
\hline -"Badiene Gokh" & 1 & 0 & 1 & 0 & 2 \\
\hline -Poverty & 2 & 3 & 6 & 3 & 14 \\
\hline -High price of iron-rich foods at the market & 1 & 3 & 0 & 3 & 7 \\
\hline \multicolumn{6}{|l|}{ Facilitating factors } \\
\hline -Resources & 6 & 1 & 3 & 5 & 15 \\
\hline
\end{tabular}

${ }^{\dagger}$ Non-Governmental Organisation. 


\section{Appendix Table 2: $\quad$ Items under each different construct of the initial questionnaire}

\begin{tabular}{|c|}
\hline Constructs \\
\hline \hline Intention (INT) \\
What is your personal position on the following \\
\cline { 2 - 2 } \begin{tabular}{c} 
statements? \\
\cline { 2 - 2 }
\end{tabular}
\end{tabular}

Behavioural beliefs (BB)

To what extent do you agree or disagree with the following statements?

\section{ltems}

1- I intend to give iron-rich foods to my child aged 6-23 months at least once a day.

2- I will give iron-rich foods to my child aged 6-23 months at least once a day.

3- How do you rate the chance that you give iron-rich foods to your child aged 6-23 months at least once a day?

1-If you give iron-rich foods to your child aged 6-23 months at least once a day, your child will be healthy.

2-If you give iron-rich foods to your child aged 6-23 months at least once a day, your child will grow up well.

3- If you give iron-rich foods to your child aged 6-23 months at least once a day, your child will have a lot of blood in his/her body.

4- If you give iron-rich foods to your child aged 6-23 months at least once a day, your child will be intelligent.

5-If you give iron-rich foods to your child aged 6-23 months at least once a day, your child will have a lot of vitamins in his/her body.

6-From the age 6 months, your child can eat all iron-rich foods without exception.

7-If you give iron-rich foods to your child aged 6-23 months at least once a day, your child will have diarrhoea.

8- If you give an iron-rich food like fish to your child aged 6-23 months at least once a day, the bones will block his/her throat.

9-If you give iron-rich foods to your child aged 6-23 months at least once a day, it will cause vomiting to your child.

10-For you, it is too early from the age of 6 months to give iron-rich foods to your child at least once a day.

11- If you give iron-rich foods to your child aged 6-23 months at least once a day, your child will suffer from intestinal worms.

Evaluate consequences (EC)

Normative beliefs (NB)

Do you think the following people or groups of people would approve or disapprove of giving iron-rich foods to your child aged 6-23 months at least once a day?
1-For you, the fact that your child aged 6-23 months is in good health is ..

2-For you, the fact that your child aged 6-23 months has good growth is ...

3-For you, the fact that your child aged 6-23 months has a lot of blood in his/her body is ...

4-For you, the fact that your child aged 6-23 months is intelligent is ...

5-For you, the fact that your child aged 6-23 months has a lot of vitamins in his body is ...

6-For you, the fact that your child aged 6-23 months has diarrhoea is..

7-For you, the fact that your child aged 6-23 months vomits is ...

8-For you, the fact that fish bones can block the throat of your child aged 6-23 months is ...

9- For you, the fact that your child aged 6-23 months suffers from intestinal worms is ..

\begin{tabular}{|c|}
\hline 1-Nurses \\
\hline 2-Your husband \\
\hline 3-Your mother-in-law \\
\hline 4- Your mother \\
\hline 5-Other mothers of the village \\
\hline 6-Community relays \\
\hline 7-"Badiene Gokh" \\
\hline 8-NGOs / associations \\
\hline 9-The nurse would approve/disapprove of giving iron-rich foods to your child aged 6-23 \\
months at least once a day.
\end{tabular}

10-Your husband would approve/disapprove of giving iron-rich foods to your child aged 623 months at least once a day.

11-Your mother-in-law would approve/disapprove of giving iron-rich foods to your child aged 6-23 months at least once a day.

12-Your mother would approve/disapprove of giving iron-rich foods to your child aged 6-23 months at least once a day. 


\begin{tabular}{|c|c|}
\hline & $\begin{array}{c}\text { 13-The other mothers in the village would approve/disapprove that you give iron-rich foods } \\
\text { to your child aged 6-23 months at least once a day. }\end{array}$ \\
\hline & $\begin{array}{l}\text { 14-Community relays would approve/disapprove that you give iron-rich foods to your child } \\
\text { aged 6-23 months at least once a day. }\end{array}$ \\
\hline & $\begin{array}{c}\text { 15-The "Badiene Gokh" would approve/disapprove that you give iron-rich foods to your } \\
\text { child aged 6-23 months at least once a day. }\end{array}$ \\
\hline & $\begin{array}{c}\text { 16-NGOs / associations would approve/disapprove that you give iron-rich foods to your } \\
\text { child aged 6-23 months at least once a day. }\end{array}$ \\
\hline \multirow{8}{*}{$\begin{array}{c}\text { Motivation to comply (MC) } \\
\text { Regarding the fact to give your child aged 6- } \\
23 \text { months at least once a day iron-rich food, } \\
\text { how important is the opinion of the following } \\
\text { people or groups of people to you? }\end{array}$} & 1-Nurses. \\
\hline & 2-Your husband \\
\hline & 3-Your mother-in-law \\
\hline & 4-Your mother. \\
\hline & 5 -Other mothers of the village. \\
\hline & 6 -Community relays \\
\hline & 7-"Badiene Gokh". \\
\hline & 8-NGOs / associations. \\
\hline \multirow{8}{*}{$\begin{array}{l}\text { Regarding the fact to give iron-rich foods to } \\
\text { your child aged } 6-23 \text { months at least once a } \\
\text { day, you will likely or unlikely act according to } \\
\text { the expectations of: }\end{array}$} & 9-Nurses. \\
\hline & 10-Your husband \\
\hline & 11-Your mother-in-law \\
\hline & 12-Your mother. \\
\hline & 13-Other mothers of the village. \\
\hline & 14-Community relays \\
\hline & 15-"Badiene Gokh". \\
\hline & 16-NGOs / associations. \\
\hline \multirow{8}{*}{$\begin{array}{l}\text { Control beliefs (CB) } \\
\text { To what extent do you agree or disagree with } \\
\text { the following statements? }\end{array}$} & $\begin{array}{c}\text { 1- If I have the financial means, I am able to give iron-rich foods to my child aged 6-23 } \\
\text { months at least once a day. }\end{array}$ \\
\hline & $\begin{array}{l}\text { 2- If I have iron-rich foods in my household, I am able to give them to my child aged 6-23 } \\
\text { months at least once a day. }\end{array}$ \\
\hline & $\begin{array}{l}\text { 3- If iron-rich foods cost less in the market, I am able to give these foods to my child aged 6- } \\
\qquad 23 \text { months at least once a day }\end{array}$ \\
\hline & $\begin{array}{l}\text { 4- If iron-rich foods are available at the market, I am able to give them to my child aged 6-23 } \\
\text { months at least once a day. }\end{array}$ \\
\hline & $\begin{array}{l}\text { 5-The lack of financial means could prevent me from giving iron-rich foods to my child aged } \\
\qquad 6-23 \text { months at least once a day. }\end{array}$ \\
\hline & $\begin{array}{l}\text { 6-The absence of iron-rich foods in the market could prevent me from giving iron-rich foods } \\
\text { to my child aged 6-23 months at least once a day. }\end{array}$ \\
\hline & $\begin{array}{l}\text { 7-The absence of iron-rich foods in my household could prevent me from giving iron-rich } \\
\text { foods to my child aged 6-23 months at least once a day. }\end{array}$ \\
\hline & $\begin{array}{l}\text { 8-The expensiveness of iron-rich foods could prevent me from giving iron-rich foods to my } \\
\text { child aged 6-23 months at least once a day. }\end{array}$ \\
\hline \multirow{4}{*}{$\begin{array}{l}\text { Perceived power of control factors }(P) \text {. } \\
\text { Among the following factors that could prevent } \\
\text { you from giving iron-rich foods to your child } \\
\text { aged } 6-23 \text { months at least once a day, }\end{array}$} & 1-The lack of financial means is a... obstacle. \\
\hline & 2-The absence of iron-rich foods in the market is a...obstacle. \\
\hline & 3- The high cost of iron-rich foods in the market is a ...obstacle. \\
\hline & 4-The absence of iron-rich foods in my home is a ...obstacle. \\
\hline
\end{tabular}

Items in italics were removed in the final questionnaire. 
Appendix Table 3: Results of indices of different models tested by exploratory factorial analyses for the validation of the questionnaire $(\mathrm{N}=120)$

\begin{tabular}{|c|c|c|c|}
\hline Constructs & Model \# & KMO indices & Lambda-2 indices \\
\hline INT (3 items) & 2 (2 items) & - & 0.82 \\
\hline \multirow[t]{5}{*}{ ATT (20 items) } & 1 (20 items) & 0.67 & 0.66 \\
\hline & 2 (11 items) & 0.74 & 0.74 \\
\hline & 3 (9 items) & 0.69 & 0.60 \\
\hline & 5 (13 items) & 0.73 & 0.76 \\
\hline & 6 (12 items) & 0.73 & 0.79 \\
\hline \multirow[t]{2}{*}{ SN (32 items) } & 1 (32 items) & 0.72 & 0.94 \\
\hline & 2 (24 items) & 0.81 & 0.95 \\
\hline \multirow[t]{3}{*}{ PBC (12 items) } & 1 (12 items) & 0.82 & 0.90 \\
\hline & 2 (11 items) & 0.82 & 0.90 \\
\hline & 3 (10 items) & 0.83 & 0.91 \\
\hline Final questionnaire & (40 items) & 0.71 & 0.91 \\
\hline
\end{tabular}

KMO: Kaiser-Meyer-Olkin

${ }^{*}$ ATT (model \#6), SN (model \#4), PBC (model \#3) and INT (model \#2).

\section{REFERENCES}

[1] World Health Organization (WHO). Iron deficiency anaemia: assessment, prevention and control: a guide for programme managers. Geneva: WHO 2001.

[2] World Health Organization (WHO). The global prevalence of anaemia in 2011. Geneva: WHO 2015.

[3] World Health Organization (WHO). Nutritional anaemias: tools for effective prevention and control. Geneva: WHO 2017.

[4] Kim SS, Nguyen PH, Tran LM, Abebe Y, Asrat Y, Tharaney $\mathrm{M}$, et al. Maternal behavioural determinants and livestock ownership are associated with animal source food consumption among young children during fasting in rural Ethiopia. Matern Child Nutr 2019; 15: e12695. https://doi.org/10.1111/mcn.12695

[5] Balarajan Y, Ramakrishnan U, Özaltin E, Shankar AH, Subramanian S. Anaemia in low-income and middle-income countries. Lancet 2011; 378: 2123-2135. https://doi.org/10.1016/S0140-6736(10)62304-5

[6] Kim SS, Rawat R, Mwangi EM, Tesfaye R, Abebe Y, Baker $\mathrm{J}$, et al. Exposure to large-scale social and behavior change communication interventions are associated with improvements in infant and young child feeding practices in Ethiopia. PloS one 2016; 11: e0164800.

https://doi.org/10.1371/journal.pone.0164800

[7] Lamstein S, Stillman T, Koniz-Booher P, Aakesson A, Collaiezzi B, Williams $\mathrm{T}$, et al. Evidence of effective approaches to social and behavior change communication for preventing and reducing stunting and anemia: Report from a systematic literature review. Arlington, VA: USAID/Strengthening Partnerships, Results, and Innovations in Nutrition Globally (SPRING) Project 2014.

[8] Latham MC. Human nutrition in the developing world. FAO Food and Nutrition Series, No.29 [Internet]. 1997; ISBN 92-5103818-X.
[9] Speedy AW. Global production and consumption of animal source foods. J Nutr 2003; 133: 4048S-4053S.

https://doi.org/10.1093/jn/133.11.4048S

[10] Michie S, Prestwich A. Are interventions theory-based? Development of a theory coding scheme. Health Psychol 2010; 29: 1-8.

https://doi.org/10.1037/a0016939

[11] Glanz K, Bishop DB. The role of behavioral science theory in development and implementation of public health interventions. Annu Rev Public Health 2010; 31: 399-418. https://doi.org/10.1146/annurev.publhealth.012809.103604

[12] Lippke S, Ziegelmann JP. Theory-based health behavior change: Developing, testing, and applying theories for evidence-based interventions. Appl Psychol 2008; 57: 698716.

https://doi.org/10.1111/j.1464-0597.2008.00339.x

[13] Menon P, Covic NM, Harrigan PB, Horton SE, Kazi NM, Lamstein $\mathrm{S}$, et al. Strengthening implementation and utilisation of nutrition interventions through research: a framework and research agenda. Ann NY Acad Sci 2014; 1332: 39-59.

https://doi.org/10.1111/nyas.12447

[14] Hamilton K, Daniels L, White KM, Murray N, Walsh A. Predicting mothers' decisions to introduce complementary feeding at 6 months. An investigation using an extended theory of planned behaviour. Appetite 2011; 56: 674-681. https://doi.org/10.1016/j.appet.2011.02.002

[15] McMillan B, Conner M, Woolridge M, Dyson L, Green J, Renfrew $\mathrm{M}$, et al. Predicting breastfeeding in women living in areas of economic hardship: Explanatory role of the theory of planned behaviour. Psychol Health 2008; 23: 767-788. https://doi.org/10.1080/08870440701615260

[16] Beale D, Manstead AS. Predicting Mothers' Intentions to Limit Frequency of Infants' Sugar Intake: Testing the Theory of Planned Behavior1. J Appl Soc Psychol 1991; 21: 409-31. https://doi.org/10.1111/j.1559-1816.1991.tb00528.x 
[17] Bowling A. Mode of questionnaire administration can have serious effects on data quality. J Public Health 2005; 27: 281-91.

https://doi.org/10.1093/pubmed/fdi031

[18] White JM, Bégin F, Kumapley R, Murray C, Krasevec J. Complementary feeding practices: Current global and regional estimates. Matern Child Nutr 2017; 13: e12505. https://doi.org/10.1111/mcn.12505

[19] IFPRI. Global Nutrition Report 2016: From Promise to Impact: Ending Malnutrition by 2030. IFPRI: Washington, DC.,USA 2016.

[20] Agence Nationale de la Statistique et Démographie et ICF. Sénégal : Enquête Démographique et de Santé Continue (EDS-Continue 2012-2014), Rapport Régional. ANSD et ICF International: Dakar, Sénégal 2015.

[21] Agence Nationale de la Statistique et Démographie et ICF. Sénégal: Enquête Démographique et de Santé Continue (EDS-Continue 2017). ANSD et ICF International: Dakar, Sénégal 2018.

[22] Secrétariat Exécutif du Conseil national de Sécurité alimentaire (SECNSA). Enquête Nationale de Sécurité Alimentaire au Sénégal 2016. SECNSA: Dakar, Sénégal 2016.

[23] International Federation of Red Cross And Red Crescent Societies. Senegal: Food security crisis - Emergency plan of action (EPoA) n MDRSN015. Dakar, Senegal 2017.

[24] United States Agency for International Development (USAID). Food assistance fact sheet Senegal. Dakar, Senegal 2018.

[25] Programme Alimentaire Mondial (PAM). Analyse Globale de la Vulnérabilité, de la Sécurité Alimentaire et de la Nutrition (AGVSAN). PAM: Dakar, Sénégal 2014.

[26] Neumann C, Harris DM, Rogers LM. Contribution of animal source foods in improving diet quality and function in children in the developing world. Nutr Res 2002; 22: 193-220. https://doi.org/10.1016/S0271-5317(01)00374-8

[27] Cellule de Lutte contre la Malnutrition (CLM). Plan Stratégique Multisectoriel de la Nutrition du Sénégal, 20172021. Dakar, Sénégal 2017.

[28] Ajzen I. The theory of planned behavior. Organ Behav Hum Decis Process 1991; 50: 179-211. https://doi.org/10.1016/0749-5978(91)90020-T

[29] McDermott MS, Oliver M, Simnadis T, Beck E, Coltman T, Iverson $\mathrm{D}$, et al. The theory of planned behaviour and dietary patterns: a systematic review and meta-analysis. Prev Medi 2015; 81: 150-6 https://doi.org/10.1016/j.ypmed.2015.08.020

[30] Spinks T, Hamilton K. Investigating key beliefs guiding mothers' dietary decisions for their 2-3 year old. Appetite 2015; 89: 167-74

https://doi.org/10.1016/j.appet.2015.02.004

[31] Horodynski M, Olson B, Arndt MJ, Brophy-Herb H, Shirer K, Shemanski R. Low-income mothers' decisions regarding when and why to introduce solid foods to their infants: influencing factors. J Community Health Nurs 2007; 24: 10118.

https://doi.org/10.1080/07370010701316247

[32] Brophy-Herb HE, Silk K, Horodynski MA, Mercer L, Olson B. Key theoretical frameworks for intervention: understanding and promoting behavior change in parent-infant feeding choices in a low-income population. J Prim Prev 2009; 30: 191-208. https://doi.org/10.1007/s10935-009-0169-9

[33] Heinig MJ, Follett JR, Ishii KD, Kavanagh-Prochaska K, Cohen R, Panchula J. Barriers to compliance with infantfeeding recommendations among low-income women. J Hum Lact 2006; 22: 27-38. https://doi.org/10.1177/0890334405284333
[34] Lagerkvist CJ, Mutiso JM, Okello JJ, Muoki P, OluochKosura W, Heck S. Predictors of Intention to Integrate Biofortified Orange-fleshed Sweetpotato in Child Feeding: A Field Information Experiment in Rural Kenya. Ecol Food Nutr 2020: 1-24. https://doi.org/10.1080/03670244.2020.1759576

[35] Ministere de l'Economie, des Finances et du Plan (MEFP), ANSD. Population du Sénégal en 2017. Dakar, Sénégal 2018.

[36] Agence Nationale de la Statistique et Démographie (ANSD). Situation Économique et Sociale du Sénégal en 2016. ANSD: Dakar, Sénégal 2019

[37] Service Régional de la Statistique et de la Démographie (SRSD). Situation économique et sociale régionale de Matam 2013. Dakar, Sénégal 2015. Available from: www.ansd.sn/ressources/ses/SES-Matam-2013.pdf.

[38] Sall M. Étude sur les pratiques alimentaires et le Score de Diversité Alimentaire des Ménages dans la Région de Matam et dans le département de Podor. Rapport fianl. Dakar, Sénégal 2016.

[39] Akpaki K, Galibois I, Sall M, Blaney S. Assessing the Food Availability and Food Insecurity Situation among Communities of Matam Region, Senegal. Ecol Food Nutr 2020: 1-20.

https://doi.org/10.1080/03670244.2020.1733993

[40] Faul F, Erdfelder E, Lang A-G, Buchner A. G* Power 3: A flexible statistical power analysis program for the social, behavioral, and biomedical sciences. Behav Res Methods 2007; 39: 175-191 https://doi.org/10.3758/BF03193146

[41] Faul F, Erdfelder E, Buchner A, Lang A-G. Statistical power analyses using $G^{*}$ Power 3.1: Tests for correlation and regression analyses. Behav Res Methods 2009; 41: 11491160. https://doi.org/10.3758/BRM.41.4.1149

[42] Ajzen I, Madden TJ. Prediction of goal-directed behavior: Attitudes, intentions, and perceived behavioral control. J Exp Soc Psychol 1986; 22: 453-74.

https://doi.org/10.1016/0022-1031(86)90045-4

[43] Gagné C, Godin G. Les théories sociales cognitives: guide pour la mesure des variables et le développement de questionnaire. Groupe de recherche sur les aspects psychosociaux de la santé, École des sciences infirmières, Université Laval 1999.

[44] Ajzen I. Constructing a theory of planned behavior questionnaire. 2006; Amherst, MA: University of Massachusetts.

http://people.umass.edu/ aizen/pdf/tpb.measurement.pdf (access July 2019)

[45] Rabiee F. Focus-group interview and data analysis. Proc Nutr Soc 2004; 63: 655-660. https://doi.org/10.1079/PNS2004399

[46] Batona G, Gagnon M-P, Simonyan DA, Guedou FA, Alary M. Understanding the intention to undergo regular HIV testing among female sex workers in Benin: a key issue for entry into HIV care. J Acquir Immune Defic Syndr 2015; 68: S206S12. https://doi.org/10.1097/QAI.0000000000000452

[47] Field A. Discovering statistics using SPSS: (and sex and drugs and rock'n'roll). 2009. $3^{\text {rd }}$ edition, Sage Publications, Inc. CA, USA

[48] Callender JC, Osburn H. An empirical comparison of coefficient alpha, Guttman's lambda-2, and MSPLIT maximised split-half reliability estimates. J Educ Meas 1979; 16: 89-99. https://doi.org/10.1111/j.1745-3984.1979.tb00090.x

[49] Guttman L. A basis for analysing test-retest reliability. Psychometrika 1945; 10: 255-282. https://doi.org/10.1007/BF02288892 
[50] Godin G. Les comportements dans le domaine de la santé: comprendre pour mieux intervenir. Presses de l'Université de Montréal 2012. https://doi.org/10.4000/books.pum.8822

[51] Gareth J, Witten D, Hastie $\mathrm{T}$ et al. An Introduction to Statistical Learning: With Applications in R. Springer: New York, USA 2014

[52] Koenker R, Bassett Jr G. Robust tests for heteroscedasticity based on regression quantiles. Econometrica 1982; 50: 4361.

https://doi.org/10.2307/1912528

[53] Drost EA. Validity and reliability in social science research. Educ Res Perspect 2011; 38: 105-123.

[54] Mansoor L, Dowse R. Design and evaluation of a new pharmaceutical pictogram sequence to convey medicine usage. J Ergon Soci SA 2004; 16(2): 29-41.

[55] Kheir N, Awaisu A, Radoui A, El-Badawi A, Jean L, Dowse R. Development and evaluation of pictograms on medication labels for patients with limited literacy skills in a culturally diverse multiethnic population. Res Social Adm Pharm 2014; 10: $720-30$. https://doi.org/10.1016/j.sapharm.2013.11.003

[56] Dowse R, Ramela T, Barford K-L, Browne S. Developing visual images for communicating information about antiretroviral side effects to a low-literate population. Afr J AIDS Res 2010; 9: 213-24.

https://doi.org/10.2989/16085906.2010.530172

[57] Barros IM, Alcantara TS, Mesquita AR, Santos AC, Paixao FP, Lyra DP, Jr. The use of pictograms in the health care: a literature review. Res Social Adm Pharm 2014; 10: 704-19. https://doi.org/10.1016/j.sapharm.2013.11.002

[58] Swanson V, Power KG. Initiation and continuation of breastfeeding: theory of planned behaviour. J Adv Nurs 2005; 50: 272-82. https://doi.org/10.1111/j.1365-2648.2005.03390.x

[59] Aubel J. The role and influence of grandmothers on child nutrition: culturally designated advisors and caregivers. Matern Child Nutr 2012; 8: 19-35. https://doi.org/10.1111/j.1740-8709.2011.00333.x

[60] Karmacharya C, Cunningham K, Choufani J, Kadiyala S. Grandmothers' knowledge positively influences maternal knowledge and infant and young child feeding practices. Public Health Nutr 2017; 20: 2114-23. https://doi.org/10.1017/S1368980017000969

[61] Bourque J, Poulin N, Cleaver A. Évaluation de l'utilisation et de la présentation des résultats d'analyses factorielles et d'analyses en composantes principales en éducation. Rev Sci Éduc 2006; 32: 325-44. https://doi.org/10.7202/014411ar

https://doi.org/10.6000/1929-4247.2021.10.03.2

(c) 2021 Akpaki et al.; Licensee Lifescience Global.

This is an open access article licensed under the terms of the Creative Commons Attribution Non-Commercial License (http://creativecommons.org/licenses/by-nc/3.0/) which permits unrestricted, non-commercial use, distribution and reproduction in any medium, provided the work is properly cited. 